\title{
Research on dynamic characteristics of cable-stayed bridge
}

\author{
Kongliang Chen ${ }^{1, a^{*}}$ Ronghui Wang 2 ,b \\ ${ }^{1}$ School of Civil Engineering and architecture, WuYi University ,Jiangmen, China. \\ ${ }^{2}$ School of Civil Engineering and Transportation, South China University of Technology,Guangzhou, \\ China \\ ackongliang@163.com , brhwang@scut.edu.cn,
}

Keywords: Cable-stayed bridge, Vibration, Bridge panel, Parametric Analysis

Abstract: For three-tower cable-stayed bridge, the dynamic characteristics of the structure is studied by establishment of the finite element model. By changing structural parameters of thickness variation of the bridge panel and elastic modulus of concrete, some regularity of stiffness and dynamic properties is to find out in this article.

\section{Introduction}

Dynamic characteristics of the bridge structure is important parameters of the dynamic behavior, including natural frequencies, mode shape, which reflects the stiffness of the bridge indicators ${ }^{[1-8]}$. Dynamic characteristics of bridge structure system depends on the composition, stiffness, mass distribution, as well as supporting the boundary conditions, it is carried out for the right bridge seismic design, analysis of vehicle vibration, wind stability analysis and maintenance of great significance. It is very important to study the dynamic performance because of the new structure of three-tower cable-stayed bridge and few studies. Yueyang Dongting Lake Bridge is China's first dual cable plane full-floating cable-stayed bridge with three towers, prestressed concrete pi-type beam, of which is the span is $130+310+310+130 \mathrm{~m}$. In this paper, the research on the dynamic characteristics is based the bridge, providing an important reference for future seismic design of such bridge, the wind stability analysis and other dynamic analysis.

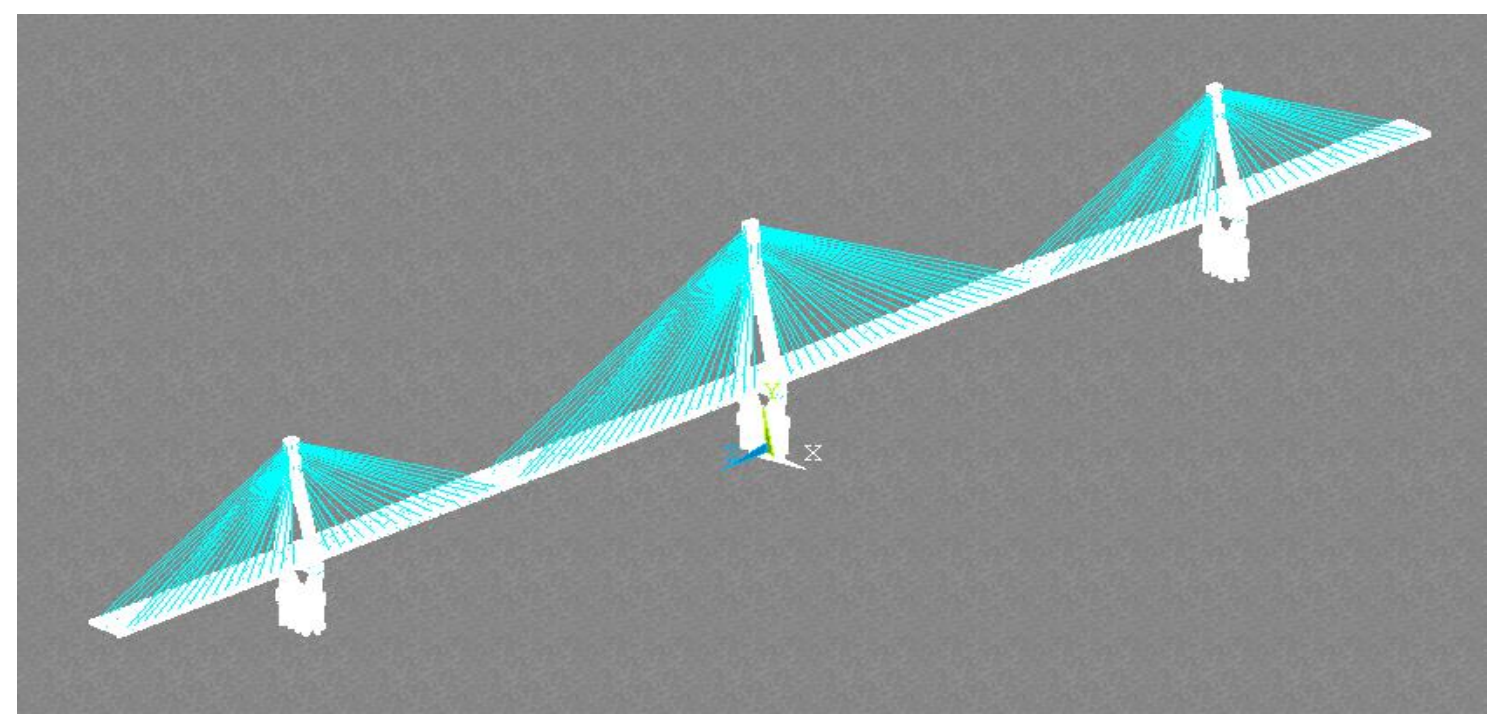

Fig.1 Calculation model 


\section{Dynamic Characteristics Analysis}

From the calculated results, the first order vibration modes and the second order vibration modes of cable-stayed bridge are torsional vibration, and the third-order mode is lateral vibration, and the fourth-order mode is vertical vibration, the results indicat that floating system of three-tower cable-stayed bridge in the outer surface of the torsional stiffness is weak, and the vertical stiffness of the plane is relatively large.

In table 1,"TV" stands for "torsional vibration", and "LV" stands for Lateral vibration, and "VV" stand for "vertical vibration"

Table 1 Modal data

\begin{tabular}{|c|c|c|c|c|c|}
\hline Order & Frequency $(\mathrm{Hz})$ & Modes & Order & Frequency $(\mathrm{Hz})$ & Modes \\
\hline 1 & 0.02 & $\mathrm{TV}$ & 6 & 0.43 & $\mathrm{VV}$ \\
\hline 2 & 0.03 & $\mathrm{TV}$ & 7 & 0.46 & $\mathrm{VV}$ \\
\hline 3 & 0.15 & $\mathrm{LV}$ & 8 & 0.66 & $\mathrm{VV}$ \\
\hline 4 & 0.22 & $\mathrm{VV}$ & 9 & 0.75 & $\mathrm{LV}$ \\
\hline 5 & 0.39 & $\mathrm{LV}$ & 10 & 0.79 & $\mathrm{VV}$ \\
\hline
\end{tabular}

\section{Impact of structural parameters on the vibration characteristics}

The effects of the changes is studied in bridge dynamic characteristics by means of different parameters in three-tower cable-stayed bridge, and the parameters are including: height bridge deck thickness, elastic modulus of concrete, the stiffness of the tower, and a small stringer stiffness, the height of tower.

\section{Thickness variation of Bridge panel}

Stiffness of the bridge deck is one of the important parameters that affect the dynamic characteristics of the three-tower cable-stayed bridge. When the bridge panel thickness respectively changes as $10 \mathrm{~cm}, 20 \mathrm{~cm}, 30 \mathrm{~cm}, 40 \mathrm{~cm}$, the first-order vertical vibration of the structure, the first-order lateral vibration and first-order torsional vibration frequency curves are shown in Fig. 2, and second-order vertical vibration, and second-order Lateral vibration, and second-order torsional vibration of the curve are shown in Fig 3.

The data shows that when the bridge panel thickness change from 0 to $40 \mathrm{~cm}$, the reduction of the first-order vertical vibration and the first-order lateral vibration is relatively slop, and first-order torsional vibration frequency remained unchanged with the change of thickness of the deck, which illustrates the bridge panel thickness changes on the rate of increase in $0-40 \mathrm{~cm}$ lateral stiffness and vertical stiffness but not obvious on torsional stiffness. 
Table 2 Modal data

\begin{tabular}{|c|c|c|c|c|c|c|c|c|c|c|}
\hline \multirow{2}{*}{ Order } & \multicolumn{2}{|c|}{ Thickness $(0)$} & \multicolumn{2}{|c|}{ Thickness $(10 \mathrm{~cm})$} & \multicolumn{2}{|c|}{ Thickness $(20 \mathrm{~cm})$} & \multicolumn{2}{|c|}{ Thickness(30 cm) } & \multicolumn{2}{|c|}{ Thickness $(40 \mathrm{~cm})$} \\
\hline & $\begin{array}{c}\text { Frequency } \\
\text { (Hz) }\end{array}$ & Modes & $\begin{array}{c}\text { Frequency } \\
\text { (Hz) }\end{array}$ & Modes & $\begin{array}{c}\text { Frequency } \\
\text { (Hz) }\end{array}$ & Modes & $\begin{array}{c}\text { Frequency } \\
\text { (Hz) }\end{array}$ & Modes & $\begin{array}{c}\text { Frequency } \\
\text { (Hz) }\end{array}$ & Modes \\
\hline 1 & 0.02 & TV & 0.02 & TV & 0.02 & TV & 0.02 & TV & 0.02 & TV \\
\hline 2 & 0.03 & TV & 0.03 & TV & 0.03 & TV & 0.03 & TV & 0.03 & TV \\
\hline 3 & 0.15 & LV & 0.15 & LV & 0.15 & LV & 0.15 & LV & 0.13 & LV \\
\hline 4 & 0.22 & vv & 0.22 & $\mathrm{vv}$ & 0.21 & vv & 0.21 & vv & 0.18 & vv \\
\hline 5 & 0.39 & LV & 0.40 & LV & 0.40 & LV & 0.40 & LV & 0.36 & LV \\
\hline 6 & 0.43 & $\mathrm{vv}$ & 0.42 & vv & 0.41 & $\mathrm{vv}$ & 0.40 & $\mathrm{vv}$ & 0.36 & $\mathrm{vv}$ \\
\hline 7 & 0.46 & vv & 0.45 & vv & 0.44 & vv & 0.43 & vv & 0.38 & vv \\
\hline 8 & 0.66 & $\mathrm{vv}$ & 0.64 & $\mathrm{vv}$ & 0.63 & $\mathrm{vv}$ & 0.61 & vv & 0.53 & vv \\
\hline 9 & 0.75 & LV & 0.76 & LV & 0.76 & $\mathrm{vv}$ & 0.74 & $\mathrm{vv}$ & 0.65 & vv \\
\hline 10 & 0.79 & vv & 0.78 & vv & 0.76 & LV & 0.76 & LV & 0.68 & LV \\
\hline
\end{tabular}

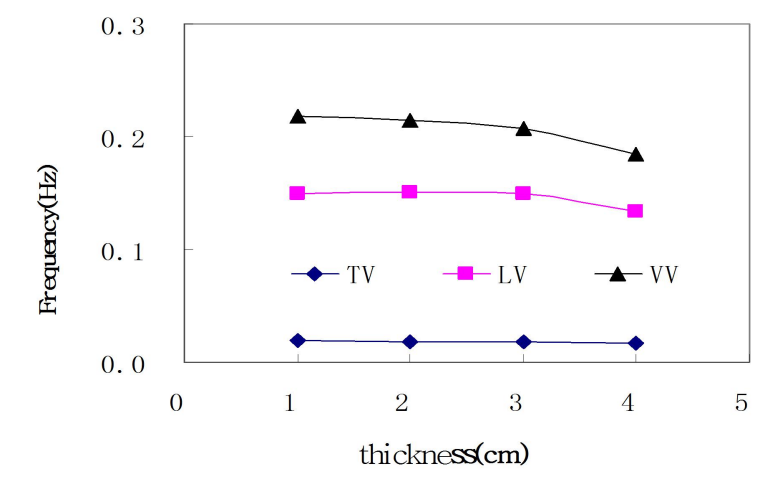

Fig.2 First-order vibration

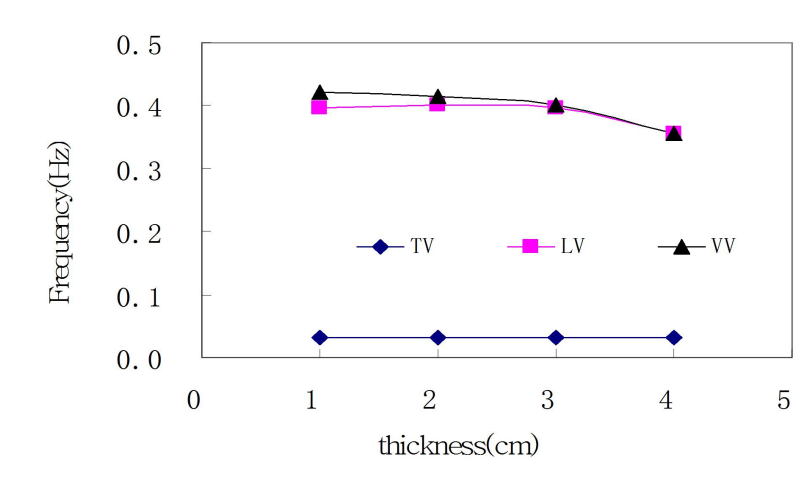

Fig.3 Second-order vibration

\section{Elastic modulus of concrete}

When the elastic modulus of concrete are changed respectively with the certain value $3.60 \mathrm{E}+$ $10,3.45 \mathrm{E}+10,3.25 \mathrm{E}+10,3.00 \mathrm{E}+10,2.55 \mathrm{E}+10$. The first-order frequency curve are shown in Fig.4, and second-order frequency curve are shown in Fig 5.

The data shows that the elastic modulus of concrete respectively changes by $3.60 \mathrm{E}+10$, $3.45 \mathrm{E}+10,3.25 \mathrm{E}+10,3.00 \mathrm{E}+10,2.55 \mathrm{E}+10$, the increase of the first-order and second-order vertical vibration is relatively flat, and the slope of the curve of first-order and second-order Lateral vibration is larger than those of vertical vibration, and first-order torsional vibration frequency keeps unchanging essentially as the elastic modulus of concrete increase, which describes the thickness of the concrete bridge deck elastic modulus change on vertical stiffness and torsional stiffness of the structure is relatively obvious, but the impact on the lateral stiffness of the structure is relatively obvious. 
Table 3 Modal data

\begin{tabular}{|c|c|c|c|c|c|c|c|c|c|c|}
\hline \multirow{2}{*}{ Order } & \multicolumn{2}{|c|}{$3.60 \mathrm{E}+10$} & \multicolumn{2}{|c|}{$3.45 \mathrm{E}+10$} & \multicolumn{2}{c|}{$3.25 \mathrm{E}+10$} & \multicolumn{2}{c|}{$3.00 \mathrm{E}+10$} & \multicolumn{2}{c|}{$2.55 \mathrm{E}+10$} \\
\cline { 2 - 11 } & $\begin{array}{c}\text { Frequency } \\
(\mathrm{Hz})\end{array}$ & Modez & $\begin{array}{c}\text { Frequency } \\
(\mathrm{Hz})\end{array}$ & Yodes & $\begin{array}{c}\text { Frequency } \\
(\mathrm{Hz})\end{array}$ & Yodes & $\begin{array}{c}\text { Frequency } \\
(\mathrm{Hz})\end{array}$ & Yodes & $\begin{array}{c}\text { Frequency } \\
\text { (Hz) }\end{array}$ & Modes \\
\hline 1 & 0.02 & TV & 0.02 & TV & 0.02 & TV & 0.02 & TV & 0.02 & TV \\
\hline 2 & 0.03 & TV & 0.03 & TV & 0.03 & TV & 0.03 & TV & 0.03 & TV \\
\hline 3 & 0.15 & LV & 0.14 & LV & 0.14 & LV & 0.14 & LV & 0.13 & LV \\
\hline 4 & 0.22 & VV & 0.22 & VV & 0.22 & VV & 0.21 & VV & 0.21 & VV \\
\hline 5 & 0.39 & LV & 0.39 & LV & 0.37 & LV & 0.36 & LV & 0.33 & LV \\
\hline 6 & 0.43 & VV & 0.43 & VV & 0.42 & VV & 0.42 & VV & 0.41 & VV \\
\hline 7 & 0.46 & VV & 0.46 & VV & 0.45 & VV & 0.44 & VV & 0.43 & VV \\
\hline 8 & 0.66 & VV & 0.65 & VV & 0.65 & VV & 0.64 & VV & 0.63 & VV \\
\hline 9 & 0.75 & LV & 0.74 & LV & 0.72 & LV & 0.69 & LV & 0.64 & LV \\
\hline 10 & 0.79 & VV & 0.79 & VV & 0.78 & VV & 0.78 & VV & 0.74 & TV \\
\hline
\end{tabular}

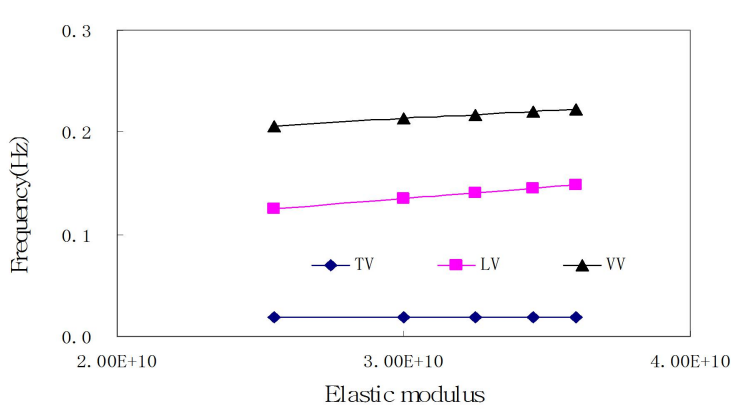

Fig.4 First-order vibration

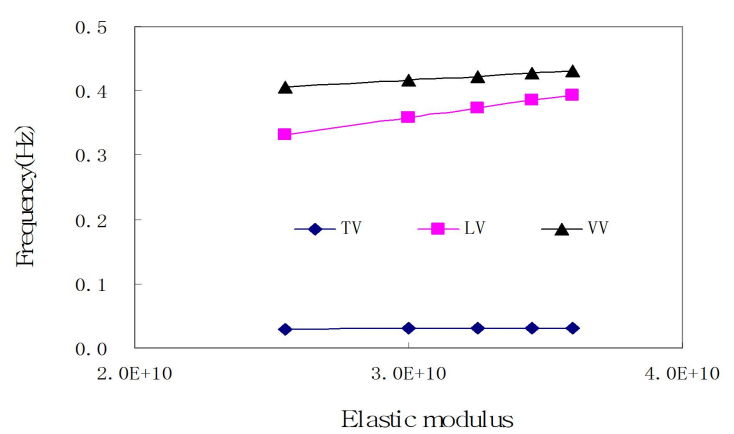

Fig.5 Second-order vibration

\section{Conclusion}

Based on finite element, dynamic analysis is carried out for floating system cable-stayed bridge with three towers, and parametric analysis carried out in accordance with factors affecting structural vibration, the conclusions are as follows:

The changes in the thickness of the bridge panel is relatively obvious influence on vertical and lateral stiffness, but the change of the torsional stiffness is negligible;

The changes in the elastic modulus of concrete are smoe impact on the torsional stiffness of the structure but is relatively small impact on the vertical stiffness and lateral stiffness.

\section{Acknowledgements}

This work was surported (No. 200820) from Department of communication of Hunan Province, and surported (No.20140080089566) from Department of communication of Jiangmen.

\section{References}

[1] Liu Airong, Zhang Junping, Yu Qicai et al.Study on dynamic properties and traveling wave effect of Xinguang Bridge. Journal of Guangzhou University Vol.6(4). (2007) P74-80

[2] Ren Weixin,Peng Xuelin,Lin Youqin. Experimental and analytical studies on dynamic characteristics span cable-stayed bridge. Engineering Structures, Vol.27, (2005). P.535-548

[3] Li Guohao. Stability and vibration of bridge structure. Beijing: China Railway Press,(2002). 
[4] Chen Huai ,Shen Zhehui ,Hu Feng, et al. Study on Dynamic Characteristics of Leaning Type Arch Bridge. Journal of Zhengzhou University: Engineering Science, Vol. 26 (4). (2005). P.25-28.

[5] Li Jingbin,Ge Sujuan,Chen Huai.Seismic Behavior Analysis of a 52m span Continuous Half through CFST Arch Bridge. World Earthquake Engineering, Vol.21(3) (2005). P.110-115.

[6] Han Wanshui, Huang Pingming, Lan Yan. Dynamic analysis of arch bridges st rengthened with high strength mico-expansive lightweight aggregate concrete. Journal of Chang'an University:Natural Science Edition, Vol.25 (4) (2005) P.44-47.

[7] Zhang Yunbo,Chen Wei,Lin Yusen. Analysisof parameters for natural vibration of long span suspension bridge. East China Highway,Vol.12 (6).(2002) P.3-6.

[8] Soyluk K. Comparison of random vibration methods formulti2support seismic excitation analysis of long-span bridges. Engineering Structures Vol.26. (2004) P.1573-1583 . 